\title{
SOME MATRIX TECHNIQUES IN GAME THEORY
}

\author{
CHI-KWONG Li AND SitA NATARAJ
}

\begin{abstract}
A short proof is given to the known result that equilibrium pairs of a two-person general-sum game can be found by solving certain systems of linear inequalities. The technique is then extended to study equilibrium pairs of evolutionary games and auction games. In the former case, evolutionary stable strategies are also determined. Furthermore, it is shown that the computation procedures can be implemented in standard linear programming packages such as LINDO or Maple, and used as education or research tools to handle examples of moderate sizes.
\end{abstract}

Mathematics subject classification (1991): 90D05, 15A39.

Key words and phrases: bimatrix game, payoff matrices, equilibrium pairs.

\section{REFERENCES}

[1] L.-E. ANDERSSON ET. AL., Criteria for copositive matrices using simplices and barycentric coordinates, Linear Algebra Appl. 220 (1995), 9-30.

[2] T. ICHIISHI, Game Theory for Economic Analysis, Academic Press, New York, 1983.

[3] H. W. KUHN, An algorithm for equilibrium points in bimatrix games, Proc. Nat. Acad. Sci. USA 47 (1961), 1657-1662.

[4] G. Owen, Game Theory (3rd ed.), Academic Press, New York, 1995.

[5] L. C. Thomas, Games: Theory and Applications, Chichister: Ellis Horwood Ltd., New York, 1984.

[6] N. N. Vorobév, Equilibrium points in bimatrix games, Theory of Probability and Its Appl. 3 (1958), 297-309.

[7] J. W. WeIBULl, Evolutionary Game Theory, MIT Press, Cambridge, 1995.

[8] H.-M. WinKELS, An algorithm to determine all equilibrium points of a bimatrix game, Game Theory and Related Topics, North-Holland, New York, 1979. 